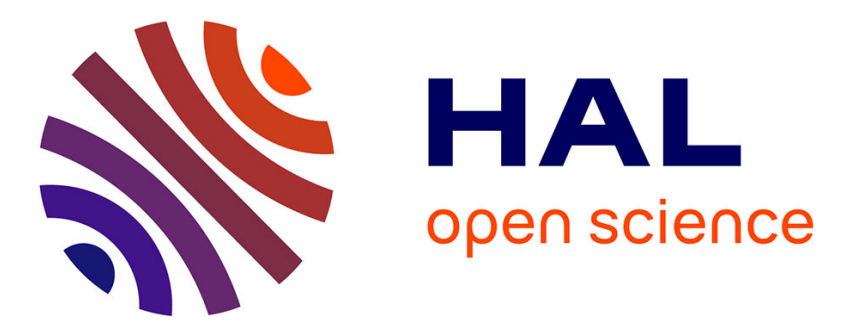

\title{
The sensitivity of gap analysis to conservation targets
}

Ruppert Vimal, Ana S.L. Rodrigues, Raphael Mathevet, John D Thompson

\section{To cite this version:}

Ruppert Vimal, Ana S.L. Rodrigues, Raphael Mathevet, John D Thompson. The sensitivity of gap analysis to conservation targets. Biodiversity and Conservation, 2011, 20, pp.531 - 543. 10.1007/s10531-010-9963-1 . hal-02456080

\section{HAL Id: hal-02456080 \\ https://hal-univ-tlse2.archives-ouvertes.fr/hal-02456080}

Submitted on 27 Jan 2020

HAL is a multi-disciplinary open access archive for the deposit and dissemination of scientific research documents, whether they are published or not. The documents may come from teaching and research institutions in France or abroad, or from public or private research centers.
L'archive ouverte pluridisciplinaire HAL, est destinée au dépôt et à la diffusion de documents scientifiques de niveau recherche, publiés ou non, émanant des établissements d'enseignement et de recherche français ou étrangers, des laboratoires publics ou privés. 


\title{
The sensitivity of gap analysis to conservation targets
}

\author{
Ruppert Vimal • Ana S. L. Rodrigues • Raphaël Mathevet • \\ John D. Thompson
}

Received: 9 June 2010/Accepted: 9 December 2010/Published online: 24 December 2010

(C) Springer Science+Business Media B.V. 2010

\begin{abstract}
A crucial stage in systematic conservation planning is the definition of explicit conservation targets to be achieved by a network of protected areas. A wide variety of targets have been employed, including overall percentage area, uniform representation of biodiversity features, and variable targets according to conservation interest. Despite the diversity of options, most studies adopt a particular set of targets without further explanation, and few have investigated the effect of target selection on their results. Here, using a data set on the distribution of plants and terrestrial vertebrates in southern France, we investigate how variation in targets can affect both stages of a gap analysis: the assessment of the completeness of an existing reserve network, and the prioritization of areas for its expansion. Target selection had a major impact on the gap analysis results, with uniform targets (50\% of each species' range) emphasizing the representation of common species, and contrasting targets (weighted according to species' conservation interest) concentrating attention on high conservation interest species and the areas where they occur. Systematic conservation planning exercises should thus pay close attention to the definition and justification of the representation targets employed.
\end{abstract}

Keywords Systematic conservation planning - Conservation targets · Protected areas . Gap analysis · Conservation priorities

R. Vimal $(\bowtie) \cdot$ A. S. L. Rodrigues · R. Mathevet · J. D. Thompson UMR 5175 Centre d'Ecologie Fonctionnelle et Evolutive, CNRS, 1919 Route de Mende, 34293 Montpellier Cedex 5, France e-mail: Ruppert.vimal@cefe.cnrs.fr
A. S. L. Rodrigues
e-mail: Ana.rodrigues@cefe.cnrs.fr
R. Mathevet
e-mail: Raphael.mathevet@cefe.cnrs.fr
J. D. Thompson
e-mail: John.thompson@cefe.cnrs.fr 


\section{Introduction}

Protected areas now occupy just over $12 \%$ of the global land area (Chape et al. 2005; Jenkins and Joppa 2009) and are arguably the most important tool for the preservation of biodiversity. Over the last three decades, the development of the field of systematic conservation planning provides a basis for the selection of priority areas for conservation and the creation of complementary networks of protected areas (Pressey et al. 1993; Margules and Pressey 2000). Conservation planning does not start from zero; most regions have already designated protected areas and subsequent conservation investment should build from them. Conservation planning thus often takes the form of a gap analysis (Scott et al. 1993), consisting of two phases. First, there is an assessment of the existing protected area network, whereby conservation 'gaps' are identified. Second, a strategic plan for expanding the existing network is developed, in order to fill in the gaps by the selection of high priority areas for conservation (Brooks et al. 2004; Rodrigues et al. 2004a, b).

A fundamental element in this process is the definition of explicit goals and conservation targets (Margules and Pressey 2000; Pressey et al. 2003). Conservation targets can be quantified as the required amounts of the distribution of a species, a habitat type or other biodiversity feature of conservation interest should be included in a conservation strategy or a regional plan (Pressey et al. 2003). They are necessary both to assess the existing protected area coverage (as gaps can only be identified once it is clear what level of representation is required) and to identify priorities for the expansion of the network (which must be strategically defined to best complement the existing network in achieving pre-defined targets).

A widely-used type of conservation target calls for the protection of a given percentage of a geographic area (Noss 1996); e.g. the call at the World Parks Congress in Bali, for governments to protect $10 \%$ of their land area (McNeely and Miller 1984), the $12 \%$ target proposed by the United Nations World Commission on Environment and Development (UNWCED 1987) and the recent recommendation to push the total surface to $17 \%$ at the Nagoya convention in 2010. Such percentage of area targets provided a representation benchmark for early gap analyses (Stoms et al. 1998; Scott et al. 2001). However, general area targets have been criticised because they are based more on the social, economic and political constrains in which conservation decisions are taken (Soule and Sanjayan 1998; Pressey et al. 2003) than on ecological and scientific assessments of conservation needs which vary across regions and biomes (Rodrigues and Gaston 2001).

In systematic conservation planning, the overall goal is to ensure the long-term persistence of a set of biodiversity features of interest and conservation targets are typically associated with individual biodiversity features (Margules and Pressey 2000). The most commonly-used target is a simple representation of each feature (e.g. Rodrigues et al. 2004b; Araujo et al. 2007), although this is admittedly insufficient as it does not guarantee long-term persistence (Araujo and Williams 2000; Rodrigues et al. 2000). More ambitious targets include multiple representations per feature (e.g. Bonn and Gaston 2005) or the protection of a minimum percentage of each feature's range (e.g. Nicholls and Margules 1993; Wright et al. 1994; Sierra et al. 2002). The conservation value of such uniform targets has been questioned because biodiversity features vary in their conservation needs and thus their priority (Soule and Sanjayan 1998; Pressey et al. 2003). Also, even though uniform targets appear to make no distinction between features, they can introduce some biases. For example, a target which requires representing each species in five sites is biased towards rare species, as these are required to be represented everywhere, while very common species are only represented in a small fraction of their range. Conversely, a target 
of representing, say, $10 \%$ of each species' range, favours widespread species, as in absolute terms $10 \%$ of a large range is a much larger area than $10 \%$ of a small range.

Recent studies have thus adopted more sophisticated methods based on different targets for particular conservation features (e.g. Desmet and Cowling 2004; Maiorano et al. 2006; Vellak et al. 2009). For example, Rodrigues et al. (2004a), Maiorano et al. (2007) set individual targets as a function of the total area occupied by each species such that very rare species were given a $100 \%$ representation target and common species $10 \%$. However such targets do not integrate levels of threat or habitat vulnerability and are faced with the difficulty of establishing priorities for locally rare species which are abundant elsewhere (Rodrigues and Gaston 2002).

Despite the wide flexibility in the available options, systematic conservation planning analyses often adopt a particular set of targets without discussing or justifying their selection, or investigating the extent to which the results are robust to variation in the targets (e.g. Powell et al. 2000; Scott et al. 2001; Rodrigues et al. 2004a, b; Araujo et al. 2007). Only a few studies have investigated the potential effects of target choice but only on the selection of priorities for new area not for the assessment of existing reserve network. Pressey and Logan (1998), Justus et al. (2008) and Rondinini et al. (2005) investigated the effect of varying the representation targets for individual features (e.g. 1, 5 or $10 \%$ of each feature's range) on the total area selected; Stewart et al. (2007) examined how increasing individual representation targets (from 5 to $50 \%$ ) over time affects longterm efficiency; Warman et al. (2004), Carvalho et al. (2010) and Drummond et al. (2009) compared minimum set results and irreplaceability values with different set of representation targets (fixed target range an minimum viable population target for example) but results were confounded by the fact that more demanding targets affect the overall area obtained. Furthermore for Drummond et al. (2009) and Carvalho et al. (2010) the different targets were a peripheral aspect of their study and there is no in-depth analyses of how the results change and why when using different targets.

In this study, we assess how the results of systematic conservation planning are influenced by defining contrasting types of targets for the representation of species within a network of protected areas. As a case study, we use an extensive dataset on the distribution of plants and terrestrial vertebrates in the Languedoc-Roussillon region of southern France. First, we investigate the effects of target definition on the evaluation of current protected area effectiveness, and second we compare the selection of priority areas for expanding the existing reserve network.

\section{Data and methods}

\section{Study area}

The Languedoc Roussillon region is an area of $27,376 \mathrm{~km}^{2}$ situated in southern France, covering most of the Mediterranean region west of the Rhône valley. The main landscape types which occur in this region are coastal landscapes with lagoons, marshes and dunes, extensive garrigues and vast areas of vines in the lowland plains, mosaic landscapes of cultivated areas and garrigues, upland limestone plateau areas, and hilly or mountainous landscapes on granite and schist in the southern tip of the Massif Central and the southeastern limits of the Pyrenees. For our spatial analyses, the study area was divided into 8,492 regular hexagonal cells, hereafter termed planning units, each measuring $3.46 \mathrm{~km}^{2}$. 
Protected area data

We compiled a geographical database of protected areas within the Languedoc Roussillon region (DREAL 2009), including 74 French statutory protected areas (one National Park, several nature reserves and prefectoral site decrees), 138 European conservation sites within the Natura 2000 network, and 4,138 sites owned by the national coastal protection agency or by local governments. We considered a planning unit as protected if more than $10 \%$ of its area was covered by at least one protected area. Under this definition, $28.4 \%$ of the study region is covered by protected areas (Fig. 2).

Species data

We used species point occurrence data for all reptile $(n=26)$, amphibian $(n=18)$ and vascular plant species $(n=3,062)$ present in the region. Reptile and amphibian data were compiled by staff of the Ecole Pratique des Hautes Etudes, while plant data were compiled by the Conservatoire Botanique National Méditerranéen de Porquerolles. These data represent the product of hundreds of naturalist inventories since 1985. Collection effort has not been uniform throughout the study region, creating biases in patterns of species' distribution. Such biases can affect the results of conservation planning (Grand et al. 2007). However, our purpose is to test the effects of considering different conservation targets on the results of conservation planning, rather than to provide specific guidance to conservation planning in this region, and so such biases are unlikely to affect our results.

\section{Species priorities}

In the context of the national inventory of high priority sites for conservation (Zones Naturelles d'Intéret Ecologique Faunistique et Floristique, INPN 2006), all species were weighted and sorted according to their conservation interest. The main criteria used for this purpose were regional rarity, in terms of the number of distinct localities where the species is present in the region, and regional responsibility, which is inversely proportional to the number of other regions in France where the species occurs. Additional criteria including international, national, or regional protection status or habitat sensitivity were also integrated to produce the list of priority species for site designation. This allows for conservation targets to be based on species distribution and local abundance.

The inventory provides seven classes for plant species and two classes (common species or conservation interest species) for reptiles and amphibians. We used this classification to distinguish four levels of conservation priority, in decreasing order of importance:

- Level 1: plant species in class $1(n=46)$ and reptiles $(n=9)$ and amphibians $(n=7)$ of conservation interest.

- Level 2: plant species in classes 2 and $3(n=216)$.

- Level 3: plant species in classes 4, 5, and $6(n=662)$.

- Level 4: plant species in class $7(n=2138)$ and common reptiles $(n=17)$ and amphibians $(n=11)$.

\section{Conservation targets}

In our study, a scenario consists of a set of pre-defined representation targets for each species. We considered two scenarios. In scenario A, all species were required to be 
represented in at least $50 \%$ of their range. In scenario B, differential targets were defined based on species' level of conservation priority (i.e. their range and local abundance). These priorities were rated at $80 \%$ coverage for species in level $1(n=62), 60 \%$ coverage for species in level $2(n=216), 15 \%$ coverage for species in level $3(n=662)$, and $5 \%$ coverage for species in level $4(n=2,166)$. In both scenarios it is assumed that conservation planning starts from the existing network of protected areas, and additional sites are selected until the respective targets are met. Scenarios were created in such a way as to provide a roughly similar protected areas' extension area, from the existing $28.4 \%$ to approximately $40 \%$. In order to obtain the same area in scenarios A and B, iterations were performed with different species targets until the same values as above were obtained. Scenarios A and B allow for a direct contrast between the effects of two types of species representation targets. Controlling for the total area across scenarios allows us to highlight differences in the results that are due to differences in the targets, rather than the result of variation in the overall area obtained.

\section{Performance of the existing reserve system}

We investigated the extent to which different targets affect results on the performance of existing protected areas in the study region. To visually show how the effectiveness can be affected by the choice of representation targets, we first plotted the frequency distribution of species according to their degree of representation, i.e. percentage of their range within the existing protected areas, for each of the four species levels. A chi-square test was used to compare the frequency distribution among levels. We then investigated the extent to which species were adequately covered by the protected area system for each of the representation targets defined in scenarios A and B. Species were considered as 'gap' species if the respective representation target was not reached and as 'covered' species otherwise (Rodrigues et al. 2004a). As a measure of the overall effectiveness of the reserve system under the two scenarios, we calculated the percentage of all species that were covered.

\section{Priorities for expanding the existing reserve system}

We investigated the effect of variation in representation targets on the selection of priorities for the expansion of the existing reserve system by analyzing how the spatial expansion of protected areas varies under the representation targets defined in scenarios $\mathrm{A}$ and $\mathrm{B}$, and by contrasting these with a control selection that is based solely on an equivalent area (such that it also results in a total protected area of $40 \%$ ) and does not integrate any species data. Analyses were performed using an adaptive annealing schedule in the Marxan software (Ball et al. 2009; Possingham et al. 2000). The control selection was implemented by using a dummy conservation feature representing the total area of the study region, setting targets for every real feature to zero, and a target for the dummy feature as the number of planning units necessary to obtain an overall area (including existing protected areas) of about $40 \%$ of the study region.

A boundary length modifier was set for each scenario to produce a final protected area network with approximately the same perimeter/area ratio as that in the present network. Consequently, in both scenarios as well as in the control selection, the proposed new planning units were preferentially adjacent to currently protected areas. This procedure was adopted because in a real-life conservation planning exercise it is likely that new conservation areas would be defined preferentially by the expansion of existing ones, and 
because from the perspective of the long-term ecological sustainability of the reserve network it is desirable that whenever possible protected areas are well connected (Stewart and Possingham 2005; Van Teeffelen et al. 2006). A consequence of this method is that it is likely to increase the similarity between the solutions found in each scenario, as they will all be biased towards sites adjacent to existing protected areas. However the control selection provides a null model of what would be expected simply from an equivalent expansion of the protected areas network under this "connectivity constraint". We obtained 100 solutions for each of the two scenario and control selection.

In order to investigate the spatial distribution of proposed expansion areas under the two scenarios and the control selection, we computed the irreplaceability of each site across the 100 solutions obtained. The irreplaceability of a planning unit reflects how important its inclusion in a network of protected areas is to meet the predefined representation targets (Pressey 1994). In this study we obtained a continuous measure of irreplaceability based on the fraction of all the feasible solutions that include the spatial unit under question. Irreplaceability was mapped for each of the two scenarios as well as for the control selection, and results compared visually. In addition, we compared the extent to which highly irreplaceable sites ( $\geq 90 \%$ irreplaceability) in one scenarios matched those in the other and in the control selection. For each pairwise comparison of irreplaceability we calculated two values. Firstly, we used Jaccard's similarity coefficient to measure the extent of overlap among highly irreplaceable planning units. This is calculated as $a /(a+b+c)$, where $a$ represents the number of highly irreplaceable units that are shared between the two cases being compared, and $b$ and $c$ represent the number of sites that are highly irreplaceable in one of the cases and not in the other. Secondly, we quantified overlap as the proportion of highly irreplaceable sites for a given case that are also highly irreplaceable in another.

Finally, we investigated explanations for dissimilarities found between scenarios A and B by analyzing how spatial distribution of irreplaceability values is influenced by underlying biodiversity patterns. To do so, we selected the highly irreplaceable planning units exclusive to each scenario and compared their mean values of total richness for species priority levels 1 and 2 and then for species priority levels 3 and 4 . The significance of these differences was tested with a Student's $t$-test.

All analyses and data manipulation were performed with Quantum Gis 1.0.2, ArcGis 9.3, Postgre SQL 8.4, Postgis 1.4 and R 2.9.1 software.

\section{Results and discussion}

Performance of the existing reserve system

The selection of different species representation targets led to very different conclusions on the effectiveness of existing protected areas (Fig. 1; Table 1). A uniform representation target of $50 \%$ of each species (scenario A) resulted in the alarming conclusion that $58.3 \%$ of all species are gaps, compared to a reassuring evaluation of $7.5 \%$ of gap species when considering differential targets (scenario B). The overall assessment of the protected area effectiveness is therefore extremely sensitive to differences in the definition of targets, even when controlling for the overall area selected.

The identity of gap species was also highly affected by the representation target (Table 1). In our example, there were marked differences in the degree of protected area coverage amongst the four species priority levels $\left(\chi^{2}=594.7, P<0.0001\right)$. The proportion of species for which the conservation target was attained (in terms of coverage by 

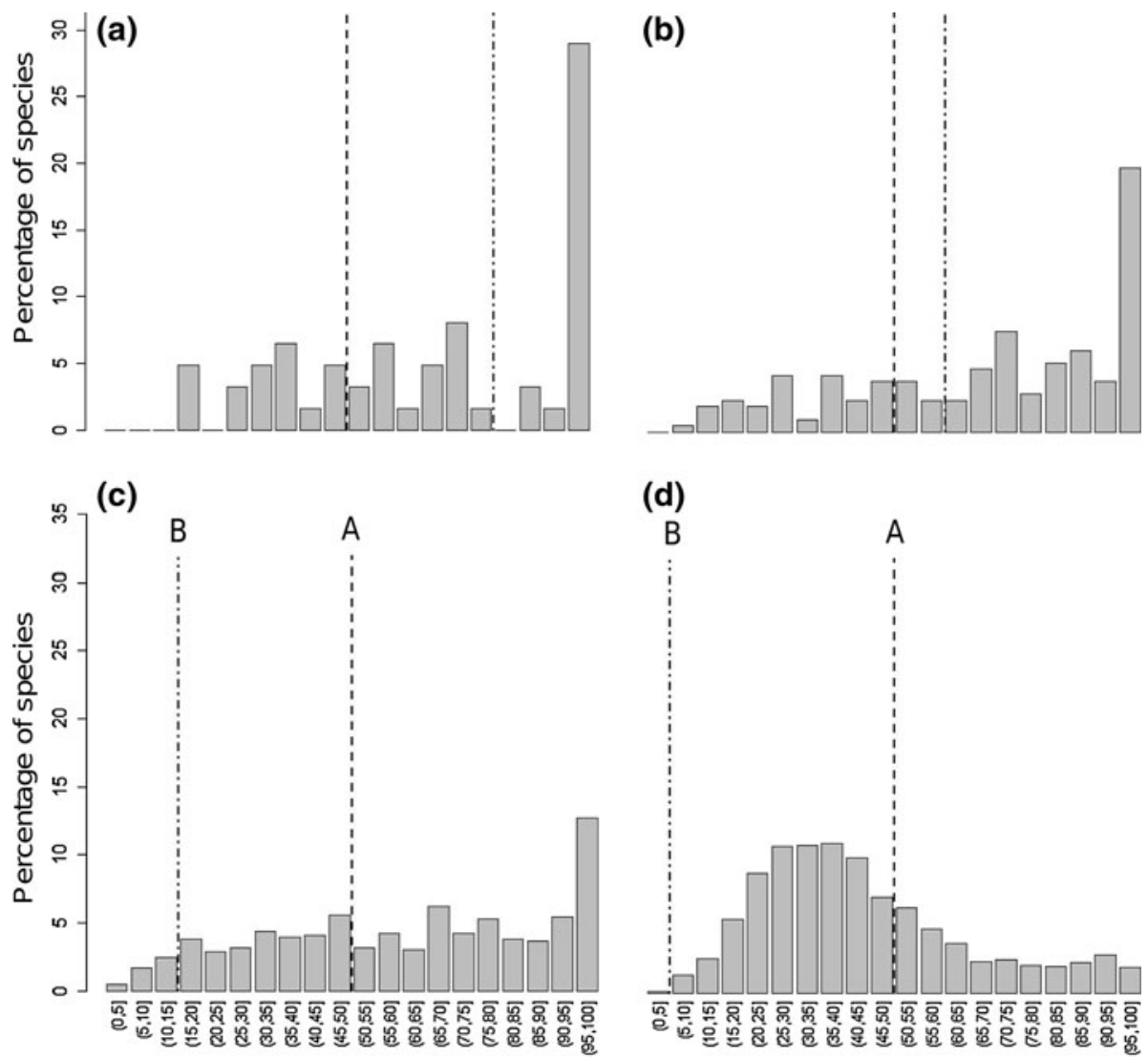

(d)

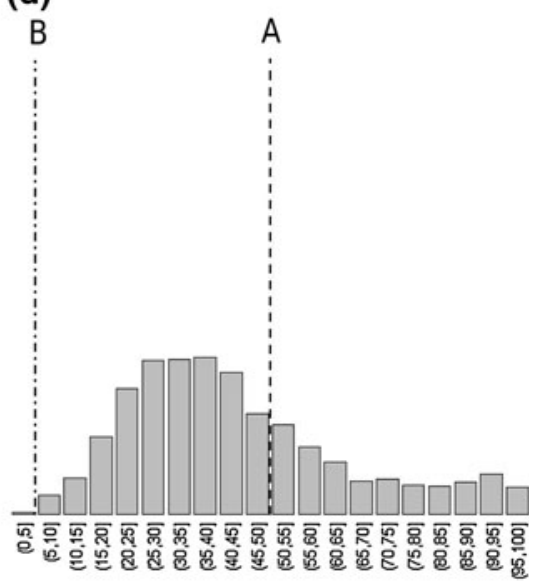

Percentage of species' range within protected areas

Fig. 1 Frequency distribution of species according to their degree of representation within the existing protected area system in the Languedoc Roussillon region of southern France, for each of the four species priority levels: a level 1 (higher priority); b level 2; c level 3; d level 4 (lower priority). The vertical lines correspond to the species representation targets in either scenario A or B; in each case, species to the left of the line are gaps, and species to the right are covered

Table 1 The percentage and absolute numbers (in parentheses) of species identified as gaps (those that do not meet representation targets) in each of the priority levels $1-4$, according to scenario A or B

\begin{tabular}{llc}
\hline & Scenario A & Scenario B \\
\hline All species & $58.3 \%(1812)$ & $7.5 \%(234)$ \\
Level 1 & $27.4 \%(17)$ & $54.8 \%(34)$ \\
Level 2 & $32.9 \%(71)$ & $40.7 \%(88)$ \\
Level 3 & $38.1 \%(252)$ & $13.9 \%(92)$ \\
Level 4 & $68.0 \%(1472)$ & $0.9 \%(20)$ \\
\hline
\end{tabular}

existing protected areas) decreased with the level of conservation interest (from level 1 to 4; Fig. 1). Under scenario A, the majority of gap species (both in terms of percentage and absolute numbers) were lower priority species (levels 3 and 4). This is because uniform percentages of area targets emphasize the conservation of widespread species which are mostly low conservation interest species. For example, given that the current protected area 
network only covers $28.4 \%$ of the total surface area of the study region, any species that occurs across the entire region will necessarily be a gap species under scenario A, as only $28.4 \%$ of its range will be covered, compared to a target of $50 \%$. In our study, most of the species from level 4 have 15 to $50 \%$ of their range covered, and hence they are all gaps under scenario A (Fig. 1a). In contrast, scenario B focuses on species with higher conservation value, which are mostly rare. Accordingly, as can be seen in Table 1 and Fig. 1, within each priority level, the fraction of species identified as gaps increases progressively from level 4 (where only $0.9 \%$ of the species are considered gaps) to level $1(54.8 \%$ of species as gaps).

Our results thus demonstrate how the choice of targets affects both the number and the nature of the biodiversity features identified as being in need of additional conservation investment.

Priorities for expanding the existing reserve system

We found both similarities and differences in the spatial configuration of the highly irreplaceable areas for the expansion of the protected area network under the two scenarios considered.

The similarities correspond to regions where there is spatial overlap between highly irreplaceable areas selected under both scenarios (Fig. 2; Table 2). A possible interpretation is that these regions are the highest priorities for the expansion of the protected area network, as they are robust to the set of targets considered. However, in our case study a large part of these similarities is explained by the use of a compactness constraint that

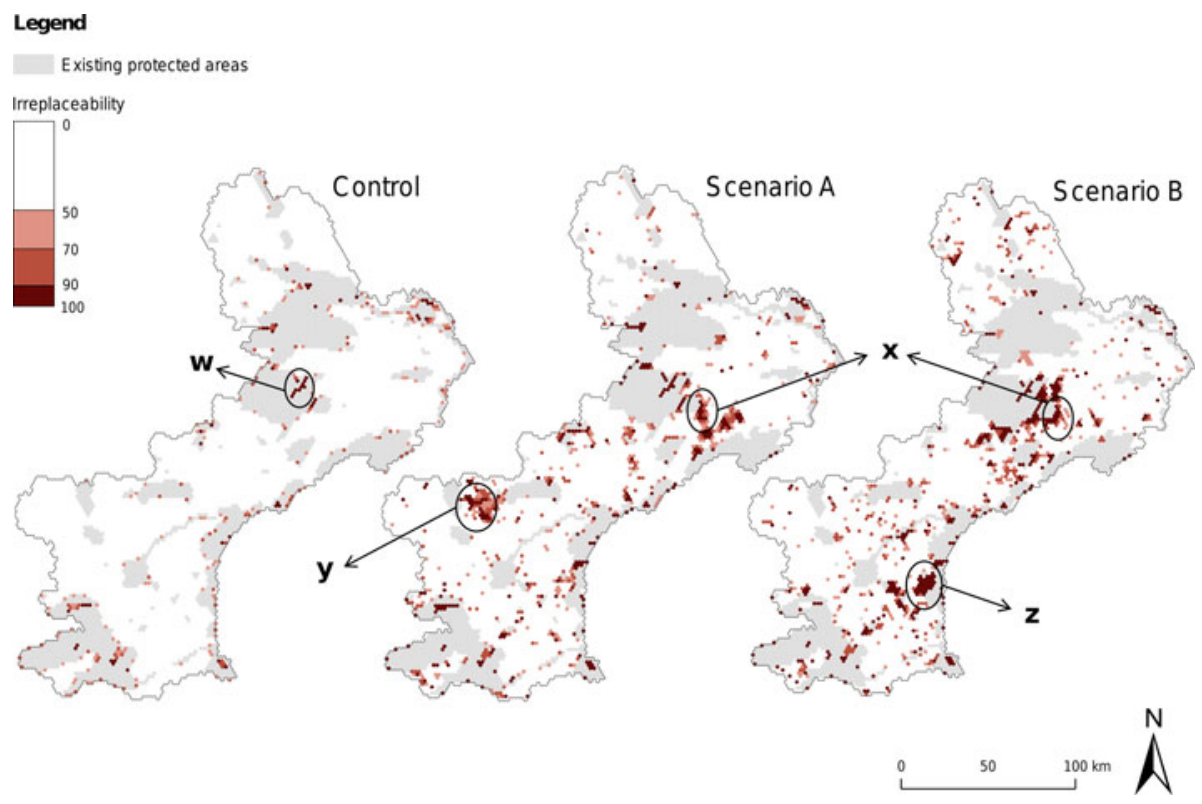

Fig. 2 Representation of irreplaceability values for each scenario: control, scenario A, scenario B. $w$ Highly irreplaceable region common to all scenarios including control; $x$ highly irreplaceable region common to scenario A and B but not to control; $y$ highly irreplaceable regions in scenario A but not in scenario B; $z$ highly irreplaceable region in scenario B but not in scenario A 
Table 2 Spatial overlap for high irreplaceability sites in scenarios A and B and between the control selection

\begin{tabular}{lllll}
\hline & $\begin{array}{l}\text { \% of total study region } \\
\text { as highly irreplaceable }\end{array}$ & \% Overlap & & Control \\
\cline { 4 - 5 } & & Scenario A & Scenario B & 20 \\
\hline Scenario A & 3.0 & $\mathrm{X}$ & 62 & 13 \\
Scenario B & 4.3 & 44 & $\mathrm{X}$ & $\mathrm{X}$ \\
Control & 0.6 & 98 & 90 & \\
\hline
\end{tabular}

favored the selection of spatially aggregated sites around existing protected areas. The effect of this constraint is clearly noticeable in the spatial arrangement of highly irreplaceable sites in the control scenario (Fig. 2). And indeed, the great majority of planning units selected in the control scenario are also highly irreplaceable in scenarios A and B (Table 2). We can thus assume that the irreplaceability of these planning units in scenarios $\mathrm{A}$ and $\mathrm{B}$ is more due to their spatial location (adjacent to existing protected areas) than to their species composition (for example, zone "w" in Fig. 2). However, this alone does not explain the high level of coincidence between highly irreplaceable sites in scenarios A and B. About half of highly irreplaceable planning units are selected by both scenarios (Table 2), including regions that are not highlighted in the control selection (e.g. zone " $x$ " in Fig. 2). In these cases, it is likely that species composition is such that these sites are particularly suitable for the expansion of the protected area networks under both types of representation targets. Extremely rare species can explain some situations, as for a species with only one occurrence in the study area, the site where they occur will be highly irreplaceable under a representation target of 5,50 or $80 \%$.

We also found important differences in the spatial distribution of highly irreplaceable sites (Fig. 2), illustrating how the choice of different representation targets affects the spatial location of priority areas for expanding the existing protected area network. In our example, about half of the planning units that are highly irreplaceable in one scenario are not so in the other (Table 2; sites "y" and "z" in Fig. 2) and accordingly the Jaccard coefficient for the two scenarios is weak $(J=0.34)$. These differences are likely a direct result of the different emphasis that each scenario puts on the representation of different sets of species. As discussed above, under scenario A (with a uniform representation target of $50 \%$ ) the great part of gap species are low conservation interest ones, while under scenario B (differentiated targets) the gaps are mainly high conservation interest species. (Drummond et al. 2009) also showed that an optimal solution differed in size and spatial configuration when using conservation goals favoring threatened or non threatened mammals.

Another interesting issue here is that there is typically more spatial flexibility in the choice of sites when aiming at meeting a representation target of $50 \%$ for mostly widespread species, than for targets of $80 \%$ for mostly restricted-range species. This probably explains the higher similarity between the control selection and scenario $\mathrm{A}(J=0.20)$ than with scenario B $(J=0.13)$, as the more flexible set of solutions in the former is likely to result in a stronger sensitivity to the connectivity constraint. This could also explain why under scenario A the fraction of the total area highlighted as highly irreplaceable is smaller than in scenario B (Table 2). Differences in species composition within highly irreplaceable units in each scenario shed further light on the reasons for dissimilarities in the spatial patterns observed: highly irreplaceable planning units exclusive to scenario A have higher 
species richness for common species (levels 3 and 4; $t=9, P<0.0001$ ) but lower species richness for priority species (levels 1 and 2$)(t=-11.2, P<0.0001)$ than highly irreplaceable sites exclusive to scenario B.

Overall, then, the definition of particular representation targets is likely to have a substantial impact on the areas identified as priorities for the expansion of an existing protected area network. Our study thus complements other work in different regional settings that illustrate an effect of target variation, on site selection. For example, Warman et al. (2004) detected a strong effect of conservation target on the irreplaceability value of individual sites and on the total area selected. Indeed, targets determine which biodiversity features become the focus of conservation priorities, and these features vary in their spatial distribution.

\section{Conclusions}

The move away from generalized surface area objectives for biodiversity conservation towards the elaboration of a set of explicitly defined conservation targets has become a major element in systematic conservation planning (Soule and Sanjayan 1998; Pressey et al. 2003; Solomon et al. 2003; Segan et al. 2010). Adapting this research to provide realistic targets in a regional context remains an important challenge in many areas (Carwardine et al. 2009), and several model examples from different regions of the world illustrate the way forward here (e.g. Pressey et al. 2003).

Our study highlights the drawbacks associated with the use of conservation targets based on a uniform percentage of a feature's range. The later should be used only with caution and when biodiversity data are unavailable (Svancara et al. 2005; Rondinini and Chiozza 2010). Indeed, although such targets appear to be unbiased by treating all species equally, they put strong emphasis on the conservation of widespread features. Given that these are often species or habitats of low conservation priority, use of this type of target may cause the misplacement of conservation investment. Instead, priorities associated with different biodiversity features should be assessed and used to define differential targets, the choice of which will depend both on the type of biodiversity goal and the data availability (Rondinini and Chiozza 2010). Ideally, conservation planners should define representation targets to ensure long-term persistence of features, such as the minimum viable area or population size (Solomon et al. 2003; Wiersma and Nudds 2006). This requires detailed ecological knowledge (e.g. on demography, abundance, etc.) and emphasizes the need for better knowledge of biodiversity dynamics. In practice, such data are often not available, or exist only for a small fraction of all species. However, given that targets can be defined individually, managers can integrate the available information on the best-known species and use coarser methods to differentiate amongst species. Here we have shown how a simple set of differential targets can be created, building on previous work on selecting priority species. An important point here is that the biodiversity most in need of protection from contemporary land-use change may often be poorly protected (Pressey et al. 2002). Hence, setting conservation targets should integrate a criterion that assesses vulnerability and allows for prioritization of highly vulnerable species or habitats (e.g. Gauthier et al. 2010).

Overall, our study has demonstrated that the definition of conservation targets is a crucial step in systematic conservation planning. Indeed, we found that it significantly affects the results and conclusions both in the assessment of the completeness of an existing reserve network and in creating a strategy for its expansion. We therefore 
recommend that future systematic conservation planning exercises pay particular attention to the definition and justification of the representation targets employed, to ensure that the results obtained are both appropriate and robust.

Acknowledgments We thank James Molina and Frederic Andrieu at the Conservatoire Botanique National Méditerranéen de Porquerolles and Philippe Geniez and Marc Cheylan at the CEFE for providing us with data necessary to make this study. We are grateful to staff at the Conservatoire des Espaces Naturels and to all the naturalists who collected data on which this analysis was based. We thank Hugh Possingham and Marxan users for their help with creating the control scenario. This work was funded by the Agence Nationale de la Recherche (contract 05-BDIV-014, ABIME), the EU (contract 226852, SCALES) and the Languedoc-Roussillon Regional Council.

\section{References}

Araujo MB, Williams PH (2000) Selecting areas for species persistence using occurrence data. Biol Conserv 96(3):331-345

Araujo MB, Lobo JM, Moreno JC (2007) The effectiveness of Iberian protected areas in conserving terrestrial biodiversity. Conserv Biol 21(6):1423-1432

Ball IR, Possingham HP, Watts M (2009) Marxan and relatives: software for spatial conservation prioritisation. In: Moilanen A, Wilson KA, Possingham HP (eds) Spatial conservation prioritisation: quantitative methods and computational tools, chap 14. Oxford University Press, Oxford, pp 185-195

Bonn A, Gaston KJ (2005) Capturing biodiversity: selecting priority areas for conservation using different criteria. Biodivers Conserv 14(5):1083-1100

Brooks TM, Bakarr MI, Boucher T, Da Fonseca GAB, Hilton-Taylor C, Hoekstra JM, Moritz T, Olivier S, Parrish J, Pressey RL, Rodrigues ASL, Sechrest W, Stattersfield A, Strahm W, Stuart SN (2004) Coverage provided by the global protected-area system: is it enough? Bioscience 54(12):1081-1091

Carvalho SB, Brito JC, Pressey RL, Crespo E, Possingham HP (2010) Simulating the effects of using different types of species distribution data in reserve selection. Biol Conserv 143(2):426-438

Carwardine J, Klein CJ, Wilson KA, Pressey RL, Possingham HP (2009) Hitting the target and missing the point: target-based conservation planning in context. Conserv Lett 2(1):3-10

Chape S, Harrison J, Spalding M, Lysenko I (2005) Measuring the extent and effectiveness of protected areas as an indicator for meeting global biodiversity targets. Philos Trans R Soc B 360(1454):443-455

Desmet P, Cowling R (2004) Using the species-area relationship to set baseline targets for conservation. Ecol Soc 9:2

DREAL Languedoc-Roussillon (2009) http://www.languedoc-roussillon.developpement-durable.gouv.fr/

Drummond SP, Wilson KA, Meijaard E, Watts M, Dennis R, Christy L, Possingham HP (2009) Influence of a threatened-species focus on conservation planning. Conserv Biol 24(2):441-449

Gauthier P, Debussche M, Thompson JD (2010) Regional priority setting for rare species based on a method combining three criteria. Biol Conserv 143(6):1501-1509

Grand J, Cummings MP, Rebelo TG, Ricketts TH, Neel MC (2007) Biased data reduce efficiency and effectiveness of conservation reserve networks. Ecol Lett 10(5):364-374

INPN (2006) L'inventaire ZNIEFF. Paris, France

Jenkins CN, Joppa L (2009) Expansion of the global terrestrial protected area system. Biol Conserv 142(10):2166-2174

Justus J, Fuller T, Sarkar S (2008) Influence of representation targets on the total area of conservation-area networks. Conserv Biol 22(3):673-682

Maiorano L, Falcucci A, Boitani L (2006) Gap analysis of terrestrial vertebrates in Italy: priorities for conservation planning in a human dominated landscape. Biol Conserv 133(4):455-473

Maiorano L, Falcucci A, Garton EO, Boitani L (2007) Contribution of the natura 2000 network to biodiversity conservation in Italy. Conserv Biol 21(6):1433-1444

Margules CR, Pressey RL (2000) Systematic conservation planning. Nature 405(6783):243-253

McNeely JA, Miller KR (1984) National parks, conservation, and development: the role of protected areas in sustaining society. Smithsonian Institution Press, Washington

Nicholls AO, Margules CR (1993) An upgraded reserve selection algorithm. Biol Conserv 64(2):165-169

Noss R (1996) Protected areas-how much is enough? National parks and protected areas: their role in environmental protection. Blackwell Science, Cambridge 
Possingham HP, Ball IR, Andelman S (2000) Mathematical methods for identifying representative reserve networks. In: Ferson S, Burgman M (eds) Quantitative methods for conservation biology. Springer, New York

Powell GVN, Barborak J, Rodriguez M (2000) Assessing representativeness of protected natural areas in Costa Rica for conserving biodiversity: a preliminary gap analysis. Biol Conserv 93(1):35-41

Pressey RL (1994) Ad hoc reservations-forward or backward steps in developing representative reserve systems. Conserv Biol 8(3):662-668

Pressey RL, Logan VS (1998) Size of selection units for future reserves and its influence on actual vs targeted representation of features: a case study in western New South Wales. Biol Conserv 85(3):305-319

Pressey RL, Humphries CJ, Margules CR, Vanewright RI, Williams PH (1993) Beyond opportunism-key principles for systematic reserve selection. Trends Ecol Evol 8(4):124-128

Pressey RL, Whish GL, Barrett TW, Watts ME (2002) Effectiveness of protected areas in north-eastern New South Wales: recent trends in six measures. Biol Conserv 106(1):57-69

Pressey RL, Cowling RM, Rouget M (2003) Formulating conservation targets for biodiversity pattern and process in the Cape Floristic Region, South Africa. Biol Conserv 112(1-2):99-127

Rodrigues ASL, Gaston KJ (2001) How large do reserve networks need to be? Ecol Lett 4(6):602-609

Rodrigues ASL, Gaston KJ (2002) Rarity and conservation planning across geopolitical units. Conserv Biol 16(3):674-682

Rodrigues ASL, Gaston KJ, Gregory RD (2000) Using presence-absence data to establish reserve selection procedures that are robust to temporal species turnover. Proc R Soc Lond B 267:897-902

Rodrigues ASL, Akcakaya HR, Andelman SJ, Bakarr MI, Boitani L, Brooks TM, Chanson JS, Fishpool LDC, Da Fonseca GAB, Gaston KJ, Hoffmann M, Marquet PA, Pilgrim JD, Pressey RL, Schipper J, Sechrest W, Stuart SN, Underhill LG, Waller RW, Watts MEJ, Yan X (2004a) Global gap analysis: priority regions for expanding the global protected-area network. Bioscience 54(12):1092-1100

Rodrigues ASL, Andelman SJ, Bakarr MI, Boitani L, Brooks TM, Cowling RM, Fishpool LDC, da Fonseca GAB, Gaston KJ, Hoffmann M, Long JS, Marquet PA, Pilgrim JD, Pressey RL, Schipper J, Sechrest W, Stuart SN, Underhill LG, Waller RW, Watts MEJ, Yan X (2004b) Effectiveness of the global protected area network in representing species diversity. Nature 428(6983):640-643

Rondinini C, Chiozza F (2010) Quantitative methods for defining percentage area targets for habitat types in conservation planning. Biol Conserv 143(7):1646-1653

Rondinini C, Stuart S, Boitani L (2005) Habitat suitability models and the shortfall in conservation planning for African vertebrates. Conserv Biol 19(5):1488-1497

Scott JM, Davis F, Csuti B, Noss RF, Butterfield B, Groves C, Anderson H, Caicco S, D'Erchia F, Edwards TC, Uliman J, Wright RG (1993) Gap analysis: a geographical approach to protection of biological diversity. Wildl Monogr 123:1-41

Scott JM, Davis FW, McGhie RG, Wright RG, Groves C, Estes J (2001) Nature reserves, do they capture the full range of America's biological diversity? Ecol Appl 11:999-1007

Segan DB, Carwardine J, Klein C, Grantham H, Pressey RL (2010) Can we determine conservation priorities without clear objectives? Biol Conserv 143(1):2-4

Sierra R, Campos F, Chamberlin J (2002) Assessing biodiversity conservation priorities: ecosystem risk and representativeness in continental Ecuador. Landsc Urban Plan 59(2):95-110

Solomon M, Van Jaarsveld AS, Biggs HC, Knight MH (2003) Conservation targets for viable species assemblages? Biodivers Conserv 12(12):2435-2441

Soule ME, Sanjayan MA (1998) Ecology—conservation targets: do they help? Science 279(5359):2060-2061

Stewart RR, Possingham HP (2005) Efficiency, costs and trade-offs in marine reserve system design. Environ Model Assess 10(3):203-213

Stewart RR, Ball IR, Possingham HP (2007) The effect of incremental reserve design and changing reservation goals on the long-term efficiency of reserve systems. Conserv Biol 21(2):346-354

Stoms DM, Davis FW, Driese KL, Cassidy KM, Murray MP (1998) Gap analysis of the vegetation of the intermountain semi-desert ecoregion. Gt Basin Nat 58(3):199-216

Svancara LK, Brannon R, Scott JM, Groves CR, Noss RF, Pressey RL (2005) Policy-driven versus evidencebased conservation: a review of political targets and biological needs. Bioscience 55(11):989-995

United Nations World Commission on Environment and Development (1987) Our common future. Oxford University Press, Oxford

Van Teeffelen AJA, Cabeza M, Moilanen A (2006) Connectivity, probabilities and persistence: comparing reserve selection strategies. Biodivers Conserv 15(3):899-919

Vellak A, Tuvi EL, Reier U, Kalamees R, Roosaluste E, Zobel M, Partel M (2009) Past and present effectiveness of protected areas for conservation of naturally and anthropogenically rare plant species. Conserv Biol 23(3):750-757 
Warman LD, Sinclair ARE, Scudder GGE, Klinkenberg B, Pressey RL (2004) Sensitivity of systematic reserve selection to decisions about scale, biological data, and targets: case study from Southern British Columbia. Conserv Biol 18(3):655-666

Wiersma YF, Nudds TD (2006) Conservation targets for viable species assemblages in Canada: are percentage targets appropriate? Biodivers Conserv 15(14):4555-4567

Wright RG, Maccracken JG, Hall J (1994) An ecological evaluation of proposed new conservation areas in Idaho-evaluating proposed Idaho national-parks. Conserv Biol 8(1):207-216 